\title{
A New Index of Housing Sentiment
}

\author{
Lasse Bork, Stig V. Møller and Thomas Q. Pedersen
}

CREATES Research Paper 2016-32 


\title{
A New Index of Housing Sentiment*
}

\author{
Lasse Bork \\ Aalborg University
}

\author{
Stig V. Møller \\ Aarhus University
}

November 11, 2016

\author{
Thomas Q. Pedersen \\ Aarhus Univeristy
}

\begin{abstract}
We propose a new measure for housing sentiment and show that it accurately tracks expectations about future house price growth rates. We construct the housing sentiment index using partial least squares on household survey responses to questions about buying conditions for houses. We find that housing sentiment explains a large share of the time-variation in house prices during both boom and bust cycles and it strongly outperforms several macroeconomic variables typically used to forecast house prices.
\end{abstract}

Keywords: Housing sentiment; house price forecastability; partial least squares; dynamic model averaging.

JEL: C53; E3; G1.

\footnotetext{
${ }^{*}$ We thank Cindy Soo for useful comments. We acknowledge support from The Danish Council of Independent Research (DFF - 4003-00022) and CREATES, Center for Research in Econometric Analysis of Time Series (DNRF78), funded by the Danish National Research Foundation.
} 


\section{Introduction}

What drives house prices? This question has preoccupied economists and policy-makers for a long time and especially so in recent years where we have witnessed both dramatic price increases and severe price drops, not only in the U.S. but also in many other countries. The current literature contains many potential explanations for the recent volatile house price movements. Among others, these include relaxation (and subsequent tightening) of credit constraints (Mian and Sufi, 2009; Demyanyk and Van Hemert, 2011; Favilukis et al., 2013), homeowners suffering from money illusion in a period of declining inflation (Brunnermeier and Julliard, 2008), and too low interest rates due to excessively loose monetary policy (Taylor, 2014). Although acknowledging the contribution of these factors to the recent house price movements, Case et al. (2014) argue that it is important also to consider peoples' opinions about buying conditions, also referred to as housing sentiment. In support of this view, they use questionnaire survey results undertaken in 1988 and annually from 2003 through 2014, and find a strong relation between the long-term house price expectations of homebuyers and actual house price movements. The scope of their analysis in terms of formally testing the link between housing sentiment and house prices is, however, restricted due to the limited number of time-series observations. In general, the main obstacle in analysing the impact of people's opinions about buying conditions on house prices and comparing this to other competing explanations is the lack of a quantifiable measure of housing sentiment measured consistently over a sufficiently long period.

In this paper, we propose a new index of housing sentiment measured at the quarterly frequency starting in 1975. We construct the housing sentiment index based on household responses to questions regarding house buying conditions from the University of Michigan consumer survey. An appealing feature of our proposed index is that it is measured consistently over a long period, which enables us to explore the effect of housing sentiment on future house prices both in calm and turbulent periods. ${ }^{1}$ Interestingly, this new housing sentiment index contains much stronger explanatory power for future house prices than a range of other variables typically used to explain house price movements. For example, in an in-sample forecast regression using quarterly observations on the all-transactions price index of the Federal Housing Finance Administration (FHFA)

\footnotetext{
${ }^{1}$ In a recent paper, Soo (2016) pursues a similar idea of constructing a measurable index of sentiment. By quantifying the qualitative tone of local housing news, Soo constructs measures of media sentiment for 34 cities across the U.S. over the period 2000 to 2013.
} 
over the period 1975:1 to 2014:4, the housing sentiment index delivers an $R^{2}$ of 48 percent. The second-highest $R^{2}$ is 33 percent (mortgage loans outstanding) and University of Michigan's own consumer sentiment index only yields an $R^{2}$ of 10 percent. Out-of-sample analysis provides similar results. In fact, the housing sentiment index is the single best predictor of house price growth as measured by the out-of-sample $R^{2}$ (Campbell and Thompson, 2008) and forecast encompassing tests (Chong and Hendry, 1986) show that it contains information about future movements in house prices that is not already contained in typically used predictor variables.

We use partial least squares (PLS) to construct the housing sentiment index because it enables us to extract the most important information from the survey responses into an easy-to-interpret index of housing sentiment. ${ }^{2}$ PLS is designed to parsimoniously identify the relevant forecasting information from a large information space and is therefore well-suited for our purpose of constructing a single index of housing sentiment. ${ }^{3}$ While both the housing sentiment index and University of Michigan's consumer sentiment index have clear business cycle patterns, their correlation over the period 1975:1 to $2014: 4$ is only 0.41 . In particular, during the housing boom and bust period in the 2000s, the housing sentiment index shows a steady increase and decrease, respectively, while the consumer sentiment index displays much more volatile movements. In general, the housing sentiment index displays far from perfect correlation with the variables typically used to forecast house prices; it is most highly correlated with mortgage loans outstanding (0.79), while it is virtually uncorrelated with, for example, the price-rent ratio $(-0.12)$.

To establish if housing sentiment generally is a strong predictor of future house price growth, or if its predictive power is confined to certain periods, we use an approach called Dynamic Model Averaging (DMA) recently developed and motivated by Raftery et al. (2010) and Koop and Korobilis (2012). DMA allows the predictors entering the model to change at each point in time, which makes it ideal in an analysis of which predictors are most important over time. More concretely, DMA uses model probabilities as weights in model averaging and a given predictor will receive more weight at time $t$ if it has shown accurate forecast performance in the recent past. DMA therefore allows us to study the role played by housing sentiment in explaining variation in house prices over time

\footnotetext{
${ }^{2}$ Although PLS was first pioneered by Wold (1966), a new literature is now emerging on its usefulness in explaining financial market dynamics, see Kelly and Pruitt (2013, 2015) and Huang et al. (2015).

${ }^{3}$ In a related paper, Huang et al. (2015) use PLS to construct a sentiment index to forecast stock returns. Their index is based on the six individual sentiment proxies of Baker and Wurgler (2006, 2007), who instead use principal components analysis (PCA) to extract the relevant information. Huang et al. (2015) find that their sentiment index computed using PLS outperforms the one by Baker and Wurgler $(2006,2007)$ based on PCA.
} 
relative to a set of other commonly used predictors. Our analysis shows that for the out-of-sample period (1995:1 to 2014:4), the housing sentiment index delivers the highest inclusion probability of all considered predictors. Furthermore, the inclusion probability for housing sentiment is high throughout the entire out-of-sample period ranging between 0.80 and 1 , which indicates that the good performance of housing sentiment is not confined to certain periods such as the boom period in the early 2000s. In contrast, many of the other predictor variables experience volatile inclusion probabilities and they are rarely as high as the inclusion probability for housing sentiment.

In a robustness analysis, we find that housing sentiment retains its strong predictive power both over longer forecast horizons and at the state level. With forecast horizons up to four years ahead, we again find housing sentiment to be the single best predictor of house prices with out-of-sample $R^{2}$ 's of about 50 percent for horizons up to one year after which the out-of-sample $R^{2}$ falls to 27 percent at the four-year horizon. In comparison, the second best predictors using a four-year horizon only deliver out-of-sample $R^{2}$ 's of around 10 percent.

House price movements across the U.S. are often found to depend on both national and local factors (e.g. Del Negro and Otrok, 2007; Hernández-Murillo et al., 2015). We show that the national housing sentiment index carries strong predictive power across the vast majority of U.S. states. A constant mean model only performs better than the national housing sentiment index in Texas, Oklahoma, and North Dakota (states with very stable house prices also during the recent boom-bust cycle).

This paper contributes to the literature on house price forecasting (Rapach and Strauss, 2009; Ghysels et al., 2013; Bork and Møller, 2015) and, in particular, to the body of evidence on the determinants of the recent boom-bust cycle in house prices (Brunnermeier and Julliard, 2008; Mian and Sufi, 2009; Demyanyk and van Hemert, 2011; Favilukis et al., 2013; Taylor, 2014; Case et al., 2014). The paper also relates to a growing literature that seeks to quantify sentiment and explore its effect on asset prices (Baker and Wurgler, 2006, 2007; Yu and Yuan, 2011; Baker et al., 2012; Stambaugh et al., 2012; Huang et al., 2015; Soo, 2016). ${ }^{4}$

The rest of the paper is organized as follows. Section 2 describes how we construct the housing

\footnotetext{
${ }^{4}$ Baker and Wugler $(2006,2007)$ show that sentiment has a larger impact on hard to arbitrage stocks. Given the strong limits to arbitrage on the housing market, we may expect a larger role for sentiment on the housing market compared to the stock market. Furthermore, Piazzesi and Schneider (2009) show that even a small number of optimistic homebyers can have a large impact on house prices.
} 
sentiment index and shows some descriptive statistics of the index and other commonly used house price predictors. In Section 3, we forecast quarterly house price growth both in- and out-ofsample using a wide range of potential predictor variables, including the housing sentiment index. Section 4 uses DMA to study which predictor variables matter the most in forecasting house prices and whether the importance of the individual predictors changes over time. Section 5 studies the importance of the individual questions from the University of Michigan's consumer survey in constructing the housing sentiment index, including their time series pattern. In Section 6, we analyse the importance of the forecasting horizon and whether the predictive power of the housing sentiment index found for national house prices also exists at the state level. Section 7 contains some concluding remarks.

\section{The construction of a new housing sentiment index}

We use time series data from the consumer surveys of the University of Michigan to generate the housing sentiment index. Our sample is quarterly and runs from 1975:1 to 2014:4. We define housing sentiment based on the general attitude of households about house buying conditions. In particular, we consider the underlying reasons households give for their views about house buying conditions. The part of University of Michigan's consumer survey related to house buying conditions starts with the question: "Generally speaking, do you think now is a good time or a bad time to buy a house?" (Table 41 in the consumer survey). The follow-up question is: "Why do you say so?" (Table 42 in the consumer survey). In constructing the index, we focus on the responses to the follow-up question as we want to draw on the information in the underlying reasons why households believe it is a bad or good time to buy a house. Specifically, we construct the housing sentiment index based on the following ten time series from Table 42 in University of Michigan's consumer survey:

1. Good time to buy; prices are low.

2. Good time to buy; prices are going higher.

3. Good time to buy; interest rates are low.

4. Good time to buy; borrow-in-advance of rising interest rates. 
5. Good time to buy; good investment.

6. Good time to buy; times are good.

7. Bad time to buy; prices are high.

8. Bad time to buy; interest rates are high.

9. Bad time to buy; cannot afford.

10. Bad time to buy; uncertain future.

Figure 1 plots each of the ten time series to give an impression of the data. It shows the fraction of households who give the relevant reason for why it is a good or a bad time to buy a house. The households can choose more than one reason and, hence, the fractions do not sum to 100. The figure reveals several interesting patterns around the recent boom-bust cycle in house prices. Leading up to the peak in house prices, an increasing fraction of households responded that it was a good time to buy because prices were going higher and because it was a good investment. After the peak in prices these fractions dropped to virtually zero, while an increasing fraction of households responded that it was a bad time to buy because they could not afford it. At the same time there was a dramatic increase in the fraction of households who responded that it was a good time to buy because prices were low.

To aggregate the information contained in each of the ten time series into an easy-to-interpret index of housing sentiment, we follow recent work on predictive modelling and make use of PLS, see, e.g., Kelly and Pruitt $(2013,2015)$ and Huang et al. (2015). PLS filters out idiosyncratic noise from the individual time series and summarizes the most important information in a single index. PLS computes the index with explicit reference to the covariance between the target variable and the derived index. ${ }^{5}$ For our purpose, the target variable is the one-quarter ahead nominal house price growth rate, which we measure based on the all-transactions house price index available from the Federal Housing Finance Administration (FHFA). The FHFA all-transactions index is constructed using repeat-sales and refinancings on the same single-family properties.

\footnotetext{
${ }^{5}$ As an alternative to PLS, we could use PCA to construct the housing sentiment index. However, in contrast to PLS, PCA does not take into account the covariance with the target variable, which intuitively could reduce the forecasting power of a PCA based index compared to a PLS based index. Unreported results show that our PLS based housing sentiment index does indeed outperform its analog based on PCA. This is also consistent with the findings by Huang et al. (2015).
} 
We use the SIMPLS algorithm of de Jong (1993) to derive the housing sentiment index. The derived index is a linear combination of the ten sentiment series. Specifically, the housing sentiment index at time $t$ is given by $S_{t}^{H}=S_{t} w$, where $S_{t}$ is a $1 \times 10$ vector of sentiment variables at time $t$ (standardized) and the weights in the $10 \times 1$ vector $w$ follow from:

$$
w=\arg \max _{w} w^{\prime} S^{\prime} y y^{\prime} S w
$$

subject to $w^{\prime} w=1$ and where $y$ refers to the FHFA house price growth rate. Hence, the housing sentiment index is the linear combination of the original sentiment series that maximizes the covariance with the target. In section 5 , we analyse the weights on the individual time series of the PLS index.

We compare the predictive power of $S_{t}^{H}$ for future house price growth with a broad set of key economic variables. The variables are the University of Michigan's consumer sentiment index, the fed funds rate, the term spread (the difference in yields between a 10-year government bond and a 3-month T-bill), real GDP growth, real consumption growth, industrial production growth, employment growth, hours in manufacturing, building permits, mortgage loans, the price-rent ratio, inflation, and stock returns. In Table 1, we provide summary statistics for $S_{t}^{H}$ and these benchmark variables. Most of the predictor variables are highly persistent, including the housing sentiment index, which has a first-order autocorrelation coefficient of 0.95. In comparison, the first-order autocorrelation coefficients for, for example, University of Michigan's consumer sentiment index and mortgage loans outstanding are 0.92 and 0.90 , respectively.

Figure 2 plots the housing sentiment index $S_{t}^{H}$ together with University of Michigan's consumer sentiment index $S_{t}^{C} \cdot{ }^{6}$ Both $S_{t}^{H}$ and $S_{t}^{C}$ have a clear business cycle pattern. They tend to rise during business cycle expansions reaching their highest values near peaks and fall during business contractions reaching their lowest values near troughs. Clearly, however, they do not move one for one. For instance, during the housing boom in the first part of the $2000 \mathrm{~s}, S_{t}^{H}$ increased steadily and peaked around 2006, while $S_{t}^{C}$ displayed much more volatile movements during this period. Housing sentiment also declined somewhat earlier than consumer sentiment around the recent bust period. From Table 1, we see that the correlation between $S_{t}^{H}$ and $S_{t}^{C}$ is only 0.41 . In general, the housing sentiment index displays far from perfect correlation with the other predictor variables; it

\footnotetext{
${ }^{6}$ The housing sentiment index is available for download from the authors' websites.
} 
is most highly correlated with mortgage loans outstanding (0.79), while it is virtually uncorrelated with, for example, building permits (0.04) and the price-rent ratio $(-0.12)$.

\section{Forecasting regressions}

\subsection{In-sample regressions}

We start out running in-sample forecasting regressions in the form of:

$$
y_{t+1}=\alpha+\beta x_{t}+u_{t+1}
$$

where $y_{t+1}$ is the log house price growth from time $t$ to $t+1$ and $x_{t}$ is one of the predictive variables observed at time $t$ (e.g. $S_{t}^{H}$ ). The goal is to analyse the in-sample predictive power of housing sentiment and to make an initial comparison with fundamental economic variables. Table 2, Panel A reports slope estimates, Newey and West (1987) $t$-statistics with three lags, and the $R^{2}$.

Table 2, Panel A shows that $S_{t}^{H}$ is by far the single best predictor of house price growth as measured by statistical significance and the degree of predictive power. Specifically, the $R^{2}$-statistic of $47.7 \%$ implies that $S_{t}^{H}$ tracks a substantial amount of the variation in future house price movements. The coefficient on $S_{t}^{H}$ is positive such that high values of housing sentiment in cyclical upswings imply high expected growth rates in house prices. Evaluating the size of the slope coefficient, we find that an increase of one standard deviation in the housing sentiment index on average implies an increase in quarterly house price growth rate of $0.88 \%$. In comparison, in our sample the average quarterly house price growth is $1.10 \%$. The predictive variable with the second highest economic significance is mortgage loans outstanding with an $R^{2}$ of $32.8 \%$ and an impact on quarterly house price growth of $0.73 \%$ following a one standard deviation increase. ${ }^{7}$

An obvious question is whether $S_{t}^{H}$ contains useful information beyond that contained in the other predictor variables. To compare $S_{t}^{H}$ to each of the other variables, we consider the following

\footnotetext{
${ }^{7}$ Given the high degree of persistence associated with many of the predictor variables, small-sample bias is a potential concern, cf. Stambaugh (1999). However, an unreported bootstrap analysis shows that this only slightly reduces the degree of predictability by the price-rent ratio. For all other predictor variables, including housing sentiment, the results are not affected by small-sample bias.
} 
bivariate regression:

$$
y_{t+1}=\alpha+\beta S_{t}^{H}+\phi x_{t}+u_{t+1}
$$

where $x_{t}$ is one of the predictor variables apart from $S_{t}^{H}$.

The bivariate regressions in Table 2, Panel B show that $S_{t}^{H}$ drives out variables such as Michigan's consumer sentiment index, mortgage loans, employment, and the inflation rate, suggesting that the predictive content of these variables is better captured by housing sentiment. In contrast, the federal funds rate and the term spread turn highly significant in the bivariate regressions as opposed to the univariate regressions. Furthermore, the sign of their slope coefficients are now as expected; rising interest rates and a lower term spread lead to drops in house prices, and vice versa. Also real consumption and the price-rent ratio contain significant explanatory power beyond that contained

in the housing sentiment index. Hence, economic fundamentals do play a role in explaining future house prices, although their contribution compared to just using the housing sentiment index is limited as seen from the small increase in $R^{2}$. Note, however, that this comparison is made insample. In the next section and section 4.2 , in particular, we evaluate the relative importance of housing sentiment and economic fundamentals out-of-sample.

\subsection{Out-of-sample regressions}

The in-sample regressions suggest a strong relation between housing sentiment and future house price growth rates. To explore this finding further, we now turn to out-of-sample regressions based on an expanding estimation window where the housing sentiment index and all parameters are estimated recursively using only information available at the time of forecast. In this way, we mitigate any concerns about potential look-ahead biases. We compute the time $t$ forecast as:

$$
\hat{y}_{t+1}=\hat{\alpha}_{t}+\hat{\beta}_{t} x_{t}
$$

where $\hat{\alpha}_{t}$ and $\hat{\beta}_{t}$ are the estimates of $\alpha$ and $\beta$ in (2) based on data from the beginning of the sample up to quarter $t$. We compare the forecasts of the regression models with forecasts computed based on the historical average house price growth rate, i.e. the benchmark ignores information from economic variables by setting $\beta=0$ in (2). We evaluate the performance of the models using the Campbell and Thompson (2008) out-of-sample $R^{2}\left(R_{O o S}^{2}\right)$. We test the null that $R_{O o S}^{2} \leq 0$ (no 
predictability) against the alternative that $R_{O o S}^{2}>0$ using the Clark and West (2007) statistic for which the standard normal distribution is a good approximation asymptotically when comparing forecasts from nested models.

We reserve the period 1975:1-1994:4 to initial estimation such that the out-of-sample forecasts are made over the period 1995:1-2014:4. Table 3 shows that $S_{t}^{H}$ generates an $R_{O o S}^{2}$ of more than 50 percent. Accordingly, the null of no predictability is strongly rejected ( $p$-value of zero). Several of the other predictors also generate significant $R_{O o S}^{2}$ statistics, but they are all way below that of $S_{t}^{H}$.

We next directly compare the housing sentiment index to the other predictor variables (in the following referred to as benchmark models) using forecast encompassing tests. Following Chong and Hendry (1986), we regress the actual house price growth on a constant, the forecast from benchmark model $j$, and the housing sentiment forecast:

$$
y_{t+1}=\delta+\lambda_{j} \hat{y}_{t+1}^{j}+\lambda_{S^{H}} \hat{y}_{t+1}^{S^{H}}+u_{t+1}
$$

If $\lambda_{S^{H}}$ differs from zero, housing sentiment contains relevant information relative to benchmark model $j$. On the other hand, if $\lambda_{j}=0$ the housing sentiment forecast encompasses the forecast of model $j$. Table 3 reports results of running the regression in (4). We adjust for heteroscedasticity and autocorrelation using the Newey-West estimator. To ease interpretation, we impose the restriction that $\lambda_{j}+\lambda_{S^{H}}=1$. The estimates of $\lambda_{S^{H}}$ are typically close to one and are always statistically significant ( $p$-values are in parenthesis), implying that the benchmark models are incapable of encompassing the forecasts generated from the housing sentiment index. $\lambda_{j}$ is typically insignificant (at conventional significance levels), suggesting that the benchmark models do not contain relevant information that can improve upon the predictions obtained using housing sentiment. The only variable for which $\lambda_{j}$ is significantly different from zero is mortgage loans outstanding, which implies that this variable contains relevant information for predicting house prices out-of-sample beyond that contained in the housing sentiment index (albeit the weight is negative).

Taken together, the out-of-sample regressions show that the housing sentiment index contains much more predictive power than all of our proxies for economic fundamentals. This evidence suggests that there is a lot of relevant information about movements in house prices to be gained from using our new housing sentiment index. In the next section we present a more formal analysis of the 
importance of each of the predictor variables in terms of forecasting house prices.

\section{When does housing sentiment work?}

Having established that sentiment has strong predictive power for house prices when using simple OLS regressions, we now take a step further and ask whether this is also the case using a more advanced forecasting approach. The best set of predictors may change substantially over time, implying that there can be certain periods where housing sentiment contains strong predictive power and others where it does not. Accordingly, we consider Dynamic Model Averaging (DMA), which allows for both model change and parameter shifts. DMA is ideal for our purpose because it allows us to examine which variables are the most important over time. First, we introduce DMA in section 4.1. Section 4.2 then analyses which variables are used by DMA and whether this changes over time, which is followed by an analysis of the predictive performance of DMA in section 4.3.

\subsection{Dynamic Model Averaging}

Dynamic Model Averaging (DMA) is a forecasting method recently developed by Raftery et al. (2010). In the following we briefly describe how we use DMA to forecast house prices. ${ }^{8}$

DMA builds on time-varying parameter (TVP) models:

$$
\begin{aligned}
& y_{t}=x_{t-1}^{\prime} \beta_{t}+\varepsilon_{t} \\
& \beta_{t}=\beta_{t-1}+\eta_{t}
\end{aligned}
$$

where $y_{t}$ is the house price growth rate, $x_{t-1}$ is an $r$-vector of predictors (including an intercept), $\beta_{t}$ is an $j$-vector of coefficients, and the innovations are distributed as $\varepsilon_{t} \sim N\left(0, V_{t}\right)$ and $\eta_{t} \sim$ $N\left(0, W_{t}\right)$. For our purpose, $x_{t-1}$ contains the 14 variables listed in Table 1 . We estimate the housing sentiment index recursively such that we only use information available at the time of the forecast.

The TVP model in (5)-(6) can be estimated straightforwardly using Kalman filter methods. The TVP model, however, assumes that the same set of predictors should be used in all time periods,

\footnotetext{
${ }^{8}$ We refer to Raftery et al. (2010) and Koop and Korobilis (2012) for a detailed description of the DMA technique.
} 
which may not be optimal when forecasting house prices. DMA extends the TVP model by allowing for model change. To illustrate this, we consider the case of multiple models based on various subsets of the variables in $x_{t-1}$ :

$$
\begin{aligned}
y_{t} & =x_{t-1}^{(k) \prime} \beta_{t}^{(k)}+\varepsilon_{t}^{(k)} \\
\beta_{t}^{(k)} & =\beta_{t-1}^{(k)}+\eta_{t}^{(k)}
\end{aligned}
$$

where $k=1, \ldots, K$ denotes a particular model. $\varepsilon_{t}^{(k)}$ is $N\left(0, V_{t}^{(k)}\right)$ and $\eta_{t}^{(k)}$ is $N\left(0, W_{t}^{(k)}\right)$. We let $L_{t} \in\{1, \ldots, K\}$ denote a model indicator, so that $L_{t}=k$ means that model $k$ is selected at time $t$. DMA is then implemented by computing $\operatorname{Pr}\left(L_{t}=k \mid Y^{t-1}\right)$ for $k=1, \ldots, K$, where $Y^{t-1}=$ $\left\{y_{1}, \ldots, y_{t-1}\right\}$. That is, computing the probability that model $k$ should be used for forecasting at time $t$, given information through time $t-1$. We denote these model probabilities by $\pi_{t \mid t-1, k}=$ $\operatorname{Pr}\left(L_{t}=k \mid Y^{t-1}\right)$.

The idea behind DMA is to use the probabilities as model weights. Accordingly, we calculate recursive forecasts of $y_{t}$ conditional on $Y^{t-1}$ using DMA as:

$$
\hat{y}_{t}^{D M A}=\sum_{k=1}^{K} \pi_{t \mid t-1, k} x_{t-1}^{(k) \prime} \hat{\beta}_{t-1}^{(k)}
$$

where $\hat{\beta}_{t-1}^{(k)}$ is the parameter prediction.

We consider all possible combinations of the predictors, so that the number of models is $K=2^{r}$. With $r=14$, we therefore consider $K=16,384$ models in each time period. Since $K$ is large, it is not feasible to do Markov switching using a $K \times K$ transition matrix, $Q=\left(q_{k \ell}\right)$, where $q_{k \ell}=\operatorname{Pr}\left[L_{t}=\ell \mid L_{t-1}=k\right]$. The large dimension of the transition matrix would lead to imprecise inferences and excessive computation time. To overcome these problems, Raftery et al. (2010) introduce a new method based on Kalman filtering and forgetting factors.

To explain the method briefly, we first define the model prediction equation:

$$
\begin{aligned}
\pi_{t \mid t-1, k} & \equiv \operatorname{Pr}\left(L_{t}=k \mid Y^{t-1}\right) \\
& =\sum_{\ell=1}^{K} \pi_{t-1 \mid t-1, \ell} q_{k \ell}
\end{aligned}
$$


which involves the transition probability $q_{k \ell}$. Raftery et al. (2010) replaces (10) with:

$$
\pi_{t \mid t-1, k}=\frac{\pi_{t-1 \mid t-1, k}^{\alpha}}{\sum_{\ell=1}^{K} \pi_{t-1 \mid t-1, \ell}^{\alpha}}
$$

where $\alpha$ is a forgetting factor, while the model updating equation is:

$$
\pi_{t \mid t, k}=\frac{\pi_{t \mid t-1, k} f_{k}\left(y_{t} \mid Y^{t-1}\right)}{\sum_{\ell=1}^{K} \pi_{t \mid t-1, \ell} f_{\ell}\left(y_{t} \mid Y^{t-1}\right)}
$$

$f_{\ell}\left(y_{t} \mid Y^{t-1}\right)$ is the predictive density of model $\ell$, i.e. the density of a $N\left(x_{t-1}^{(\ell) \prime} \hat{\beta}_{t-1}^{(\ell)}, V_{t}^{(\ell)}+x_{t-1}^{(\ell) \prime} \Sigma_{t \mid t-1}^{(\ell)} x_{t-1}^{(\ell)}\right)$ distribution evaluated at $y_{t}$. With the forgetting factor approach, it is not necessary to use the transition matrix of the Markov chain. Instead, it is possible to do model updating and parameter updating using Kalman filtering methods.

The Kalman filter prediction of the parameters is given by:

$$
\begin{aligned}
\hat{\beta}_{t \mid t-1}^{(k)} & =\hat{\beta}_{t-1 \mid t-1}^{(k)} \\
\Sigma_{t \mid t-1}^{(k)} & =\frac{1}{\lambda} \Sigma_{t-1 \mid t-1}^{(k)}
\end{aligned}
$$

where $\lambda$ is another forgetting factor, $\Sigma_{t \mid t-1}^{(k)}$ denotes the covariance matrix of $\beta_{t-1}^{(k)}$, while the updating equations simplify to:

$$
\begin{aligned}
& \hat{\beta}_{t \mid t}^{(k)}=\hat{\beta}_{t \mid t-1}^{(k)}+\Sigma_{t \mid t-1}^{(k)} x_{t-1}^{(k) \prime}\left(V_{t}^{(k)}+x_{t-1}^{(k) \prime} \Sigma_{t \mid t-1}^{(k)} x_{t-1}^{(k)}\right)^{-1}\left(y_{t}-x_{t-1}^{(k) \prime} \hat{\beta}_{t-1}^{(k)}\right) \\
& \Sigma_{t \mid t}^{(k)}=\Sigma_{t \mid t-1}^{(k)}-\Sigma_{t \mid t-1}^{(k)} x_{t-1}^{(k) \prime}\left(V_{t}^{(k)}+x_{t-1}^{(k) \prime} \Sigma_{t \mid t-1}^{(k)} x_{t-1}^{(k)}\right)^{-1} x_{t-1}^{(k)} \Sigma_{t \mid t-1}^{(k)}
\end{aligned}
$$

The forgetting factor approach implies that estimation of the state error covariance simplifies to $W_{t}^{(k)}=\left(\lambda^{-1}-1\right) \Sigma_{t \mid t-1}^{(k)}$, which in turn leads to (14).

We need to specify $\alpha$ and $\lambda$. With quarterly data Koop and Korobilis (2012) recommend the intervals $\alpha \in(0.95,0.99)$ and $\lambda \in(0.95,0.99)$. We choose $\alpha=\lambda=0.97$, but find that the results are very robust towards other reasonable values for $\alpha$ and $\lambda .{ }^{9}$

\footnotetext{
${ }^{9}$ Similar to the methods in McCormick et al. (2012) and Bork and Møller (2015), we have analysed the case of time-varying forgetting factors where $\alpha$ and $\lambda$ are estimated recursively. This did not lead to any significant differences in the results.
} 


\subsection{Choice of variables}

DMA uses $\pi_{t \mid t-1, k}$ as weights for each of the $k=1, \ldots, K$ models. We can therefore use $\pi_{t \mid t-1, k}$ to illustrate which predictors are the most important over time. The posterior inclusion probability of a given predictive variable is defined as the probability that DMA attaches to models that include that particular predictive variable. In Figure 3, we plot posterior inclusion probabilities for each of the 14 predictive variables. The figure demonstrates that housing sentiment by far receives the most weight in the model averaging. In fact, DMA attaches a probability to housing sentiment that is close to 1 throughout the entire out-of-sample period and never falls below 0.80. Hence, there is very little variation over time with respect to the importance of including housing sentiment, which suggests that housing sentiment contains useful information not only during house price booms and busts, but also during calmer periods.

For the remaining variables the patterns in inclusion probabilities show great variation, but the inclusion probabilities are in most cases substantially below the probability that DMA attaches to housing sentiment. It is, however, important to note that economic fundamentals do play a role in explaining house prices. If not, the inclusion probabilities shown in Figure 3 would be (close to) zero. Although typically below the levels for housing sentiment index, all other predictor variables have an inclusion probability above 0.5 at one point or another during the out-of-sample period. For example, a competing explanation of the recent boom-bust cycle in house prices is relaxation (and subsequent tightening) of credit constraints. From Figure 3, we see that the importance of mortgage loans outstanding increased steadily over the period 2004-2009 and at its peak the inclusion probability was about 0.5 after which it dropped abruptly. Another competing explanation of the recent boom-bust cycle in house prices is related to interest rates. Starting in 2004, the term spread's inclusion probability increased quite dramatically and in the years 20072009 , it peaked with an inclusion probability close to 1 . Subsequently, it dropped and by the end of our sample period it was around 0.7. The results in Figure 3 thus suggest that many factors contribute to movements in house prices, but housing sentiment stands out as the most important and stable predictor variable. 


\subsection{Forecasting results}

Table 4 shows the out-of-sample results obtained using DMA. We consider two cases. First, we let DMA choose from all the variables listed in Table 1, including the housing sentiment index $(r=14, K=16,384)$. Second, to examine the importance of housing sentiment, we leave it out from the set of variables DMA can choose from $(r=13, K=8,192)$. In this way, we can assess the incremental forecasting power of housing sentiment when controlling for a standard set of key economic variables in a setting that allows for model selection and parameter shifts.

As the table shows, we achieve an $R_{O o S}^{2}$ as high as $60.7 \%$ when including housing sentiment. But leaving out housing sentiment, the $R_{O o S}^{2}$ drops to $48.9 \%$. Hence, we can explain about $12 \%$ more of the variation in the next quarter's house price growth by including $S_{t}^{H}$ in the set of predictors that DMA can choose from. These results clearly illustrate that our new housing sentiment index contains important information that key economic variables are missing.

Figure 4 plots $y_{t}$ together with $\hat{y}_{t}^{D M A}$ to visualize the out-of-sample performance of DMA. Here we include the housing sentiment index. The figure shows how DMA captures the large positive growth rates over the period from the mid 1990s up to around the mid 2000s and subsequently convincingly predicts the sharp decline in house prices. DMA also captures the positive upward trend in house prices towards the end of the sample period.

Shiller (2007) argues that the large house price boom from the late 1990s up to around the mid 2000s cannot be explained by economic fundamentals. Our results show that housing sentiment indeed has played an important role during this period but also during the subsequent bust period.

\section{Time series patterns in the PLS weights}

The underlying reason behind the strong predictive power of the housing sentiment index is that we exploit the ten sentiment variables in an optimal way based on the PLS procedure. To provide some additional insights on why the housing sentiment index works so well, we now analyse the time series patterns in the PLS weights. We focus on the four most important underlying components in the housing sentiment index. From Figure 5, we see that PLS puts the largest positive weight on the series "prices are going higher" and "good investment" and the largest negative weight on 
the series "cannot afford" and "prices are low". Thus, in high sentiment periods households are positive about housing as they believe that prices are going higher and they see housing as a good investment, while in low sentiment periods households are negative about housing as they cannot afford buying a house and believe prices are low. These four components were also highlighted in our comments to Figure 1 since they displayed interesting patterns around the boom-bust cycle in house prices. From Figure 5, it is also clear that the weights - estimated recursively during the out-of-sample window - are quite stable over time, which implies that the importance of these four components are not confined to the recent boom-bust period but holds more generally in relation to forecasting house prices. This stability in the loadings is also part of the reason why our analysis of in- and out-of-sample forecasting power yields very similar results.

\section{Robustness}

In the following, we provide robustness checks in two different directions. First, in section 6.1, we examine the predictive power of housing sentiment at long forecast horizons. Second, in section 6.2 , we examine the predictive power of housing sentiment at the state-level.

\subsection{Longer horizons}

The predictive ability of housing sentiment is not restricted to short horizons. To illustrate this, we run long-horizon forecasting regressions

$$
y_{t+h}=\alpha+\beta x_{t}+u_{t+h}
$$

where $y_{t+h}=\sum_{i=1}^{h} y_{t+i}$ is the log house price growth from time $t$ to $t+h$ and $x_{t}$ is one of the predictive variables observed at time $t$. In Figure 6, we plot the $R_{O o S}^{2}$ from out-of-sample regressions where we estimate (17) and the housing sentiment index recursively using an expanding window (with the out-of-sample period running from 1995:1 to 2014:4). We consider $h=1,2,3,4,8,12$, and 16. The figure illustrates that housing sentiment contains substantial predictive power for future house price growth, especially one to four quarters ahead. The maximum $R_{O o S}^{2}$ is obtained at $h=3$ $(56.9 \%)$ and the predictive power gradually declines thereafter. Nevertheless, at $h=16$, the $R_{O o S}^{2}$ is still as high as $27.0 \%$. We also see that the housing sentiment is a considerably better predictive 
variable than well-known macroeconomic predictive variables across all forecast horizons.

\subsection{State-level evidence}

There is compelling evidence in the literature that movements in house prices across the U.S. depend on both national and local factors, see, e.g., Del Negro and Otrok (2007) and Hernández-Murillo et al. (2015). The focus of our paper is to forecast national house prices. However, it still appears interesting, as a robustness check, to examine whether the national housing sentiment index is important for regional housing markets. Hence, for each of the 50 states, we run one-quarter ahead out-of-sample regressions over the period 1995:1 to 2014:4. We use housing sentiment as the only predictive variable. To give an overview of the results, we plot the $R_{O o S}^{2}$ across the states in Figure 7. The overall picture is that housing sentiment contains useful information for predicting house prices in the vast majority of states. The exceptions are Texas, Oklahoma, and North Dakota. These states have had stable house prices, even during the recent boom-bust cycle, which explains why housing sentiment does not play an important role in these states. ${ }^{10}$ In the remaining states, the $R_{\text {OoS }}^{2}$ ranges from $18 \%$ (South Dakota) to $65 \%$ (Washington), implying that housing sentiment is generally useful in forecasting house prices also at the state-level. ${ }^{11}$

\section{Concluding remarks}

We construct an easy-to-interpret index of housing sentiment using household survey responses to questions about house buying conditions. The housing sentiment index strongly outperforms, both with in- and out-of-sample forecast regressions, a range of other variables often used to forecast house prices, including interest rates, mortgage loans outstanding, building permits, employment, and the price-rent ratio. For forecast horizons from one quarter up to one year, the recursively estimated sentiment index is able to explain about 50 percent of future house price growth. For longer horizons, the explanatory power decreases slightly, but even with a forecast horizon of four years, the sentiment index is able to explain more than 25 percent of future house price growth.

\footnotetext{
${ }^{10}$ Baker and Wurgler (2006) also find that less volatile stocks are less affected by sentiment.

${ }^{11}$ It would be interesting to construct state-level sentiment indexes. However, we do not have access to survey data at the state-level. Baker et al. (2012) examine the impact of global and local sentiment on major stock markets and find that both help to predict stock returns.
} 
We use a technique called DMA in our out-of-sample analysis to show that housing sentiment not only performs well during periods with highly volatile house prices but also does so in calmer periods. DMA uses model averaging based on posterior inclusion probabilities, implying that a given predictive variable will receive more weight at time $t$ if it has helped to produce accurate forecasts in the recent past. For housing sentiment, the inclusion probability remains high for the entire out-of-sample period and never falls below 0.80 , while only a few of the other predictor variables experience inclusion probabilities above 0.8 , and only for a limited period of time.

In the aftermath of the recent surge and subsequent collapse in house prices, a growing literature has sought to determine the drivers of house price movements; not only during the boom-bust cycle but also in general. Our results suggest that people's views about housing are important for understanding the time-series variation in house prices and that housing sentiment is a key driver during both booms and busts as well as in less volatilie periods. 
Baker, M. \& Wurgler, J. (2006). Investor sentiment and the cross-section of stock returns. Journal of Finance, 55, 2219-2257.

Baker, M. \& Wurgler, J. (2007). Investor sentiment in the stock market. Journal of Economic Perspectives, 21, 129-152.

Baker, M., Wurgler, J. \& Yuan, Y. (2012). Global, local, and contagious investor sentiment. Journal of Financial Economics, 104, 272-287.

Bork, L. \& Møller, S.V. (2015). Forecasting house prices in the 50 states using Dynamic Model Averaging and Dynamic Model Selection. International Journal of Forecasting, 31, 63-78.

Brunnermeier, M.K. \& Julliard, C. (2008). Money illusion and housing frenzies. Review of Financial Studies, 21, 135-180.

Campbell, J. \& Thompson, S. (2008). Predicting excess stock returns out of sample: Can anything beat the historical average? Review of Financial Studies, 21, 1509-1531.

Case, K.E., Shiller, R.J. \& Thompson, A. (2014). What have they been thinking? Home buyer behavior in hot and cold markets - a 2014 update. Cowles Foundation Discussion Paper, No. 1876R.

Chong, Y. \& Hendry, D. (1986). Econometric evaluation of linear macroeconomic models. Review of Economic Studies, 53, 671-690.

Clark, T.E. \& West, K.D. (2007). Approximately normal tests for equal predictive accuracy in nested models. Journal of Econometrics, 138, 291-311.

de Jong, S. (1993). SIMPLS: An alternative approach to partial least squares regression. Chemometrics and Intelligent Laboratory Systems, 18, 251-263

Del Negro, M. \& Otrok, C. (2007). 99 luftballons: Monetary policy and the house price boom across U.S. states. Journal of Monetary Economics, 54, 1962-1985.

Demyanyk, Y. \& Van Hemert, O. (2011). Understanding the subprime mortgage crisis. Review of Financial Studies, 24, 1848-1880.

Favilukis, J., Kohn, D., Ludvigson, S. \& Van Nieuwerburgh, S. (2013). International capital flows and house prices: Theory and evidence. Housing and the Financial Crisis, Edward L. Glaeser and Todd Sinai (Eds.), University of Chicago Press, 235-299.

Ghysels, E., Plazzi, A., Valkanov, R. \& Torous, W. (2012). Forecasting real estate prices. Handbook of Economic Forecasting, G. Elliot and A. Timmermann (Eds.), 509-580.

Hernández-Murillo, R., Owyang, M.T. \& Rubio, M. (2015). Clustered housing cycles. Working Paper, Federal Reserve Bank of St. Louis.

Huang, D., Jiang, F., Tu, J. \& Zhou, G. (2015). Investor sentiment aligned: A powerful predictor of stock returns. Review of Financial Studies, 28, 791-837.

Kelly, B. \& Pruitt, S. (2013). Market expectations in the cross-section of present values, Journal of Finance, 68, 1721-1757. 
Kelly, B. \& Pruitt, S. (2015). The three-pass regression filter: A new approach to forecasting using many predictors. Journal of Econometrics, 186, 294-316.

Koop, G. \& Korobilis, D. (2012). Forecasting inflation using dynamic model averaging. International Economic Review, 53, 867-886.

McCormick, T.M., Raftery, A.E., Madigan, D. \& Burd, R.S. (2012). Dynamic logistic regression and dynamic model averaging for binary classification. Biometrics, 68, 23-30.

Mian, A. \& Sufi, A. (2009). The consequences of mortgage credit expansion: Evidence from the U.S. mortgage default crisis. Quarterly Journal of Economics, 124, 1449-1496.

Newey, W. \& West, K. (1987). A simple, positive semi-definite, heteroskedasticity and autocorrelation consistent covariance matrix. Econometrica, 55, 703-708.

Piazzesi, M. \& Schneider, M. (2009). Momentum rraders in the housing market: Survey evidence and a search Model. American Economic Review, Papers and Proceedings 99, 406-411.

Raftery, A.E., Karny, M. \& Ettler, P. (2010). Online prediction under model uncertainty via dynamic model averaging: Application to cold rolling mill. Technometrics, 52, 52-56.

Rapach, D.E. \& Strauss, J.K. (2009). Differences in housing price forecastability across US states. International Journal of Forecasting 25, 351-372.

Shiller, R. J. (2007). Understanding recent trends in house prices and home ownership. NBER Working Paper, No. 13553.

Soo, C. K. (2016). Quantifying animal spirits: News media and sentiment in the housing market. Working paper, University of Michigan.

Stambaugh, R. F. (1999). Predictive regressions. Journal of Financial Economics 54, 375-421.

Stambaugh, R. F., Yu, J., Yuan, Y. (2012). The short of it: Investor sentiment and anomalies. Journal of Financial Economics 104, 288-302.

Taylor, J.B. (2014). Causes of the financial crisis and the slow recovery: A 10-year perspective. Across the Great Divide: New Perspectives on the Financial Crisis, Martin Maily and John B. Taylor (Eds.), Hoover Press, 51-65.

Yu, J. \& Yuan, Y. (2011). Investor sentiment and the mean-variance relation. Journal of Financial Economics 100, 367-381.

Wold, H. (1966). Estimation of principal components and related models by iterative least squares. In: Krishnaiaah, P. (Ed.), Multivariate Analysis, Academic Press, New York, 391-420. 

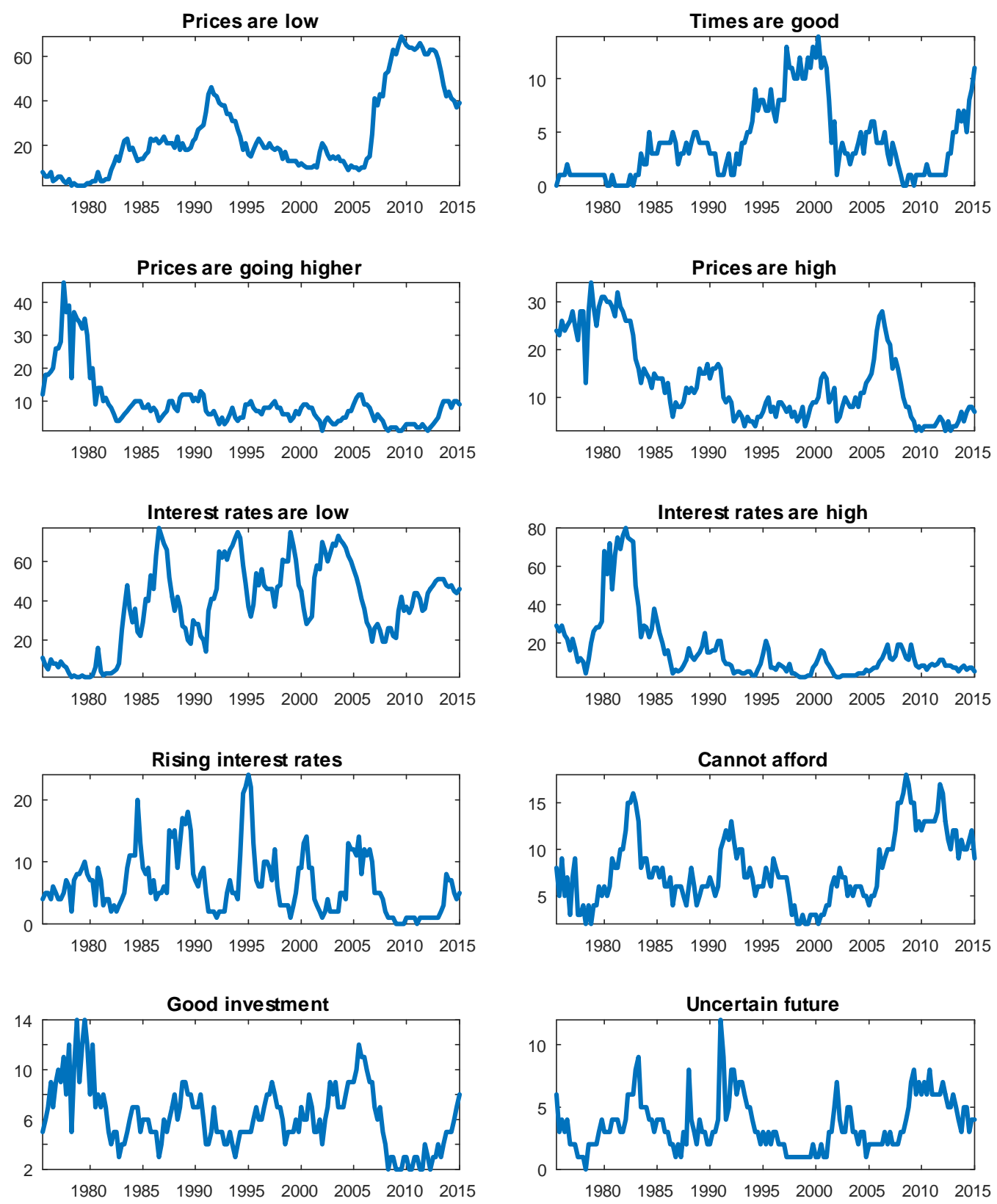

Figure 1. Sentiment variables.

The figure plots the ten sentiment variables we use to construct the housing sentiment index. 


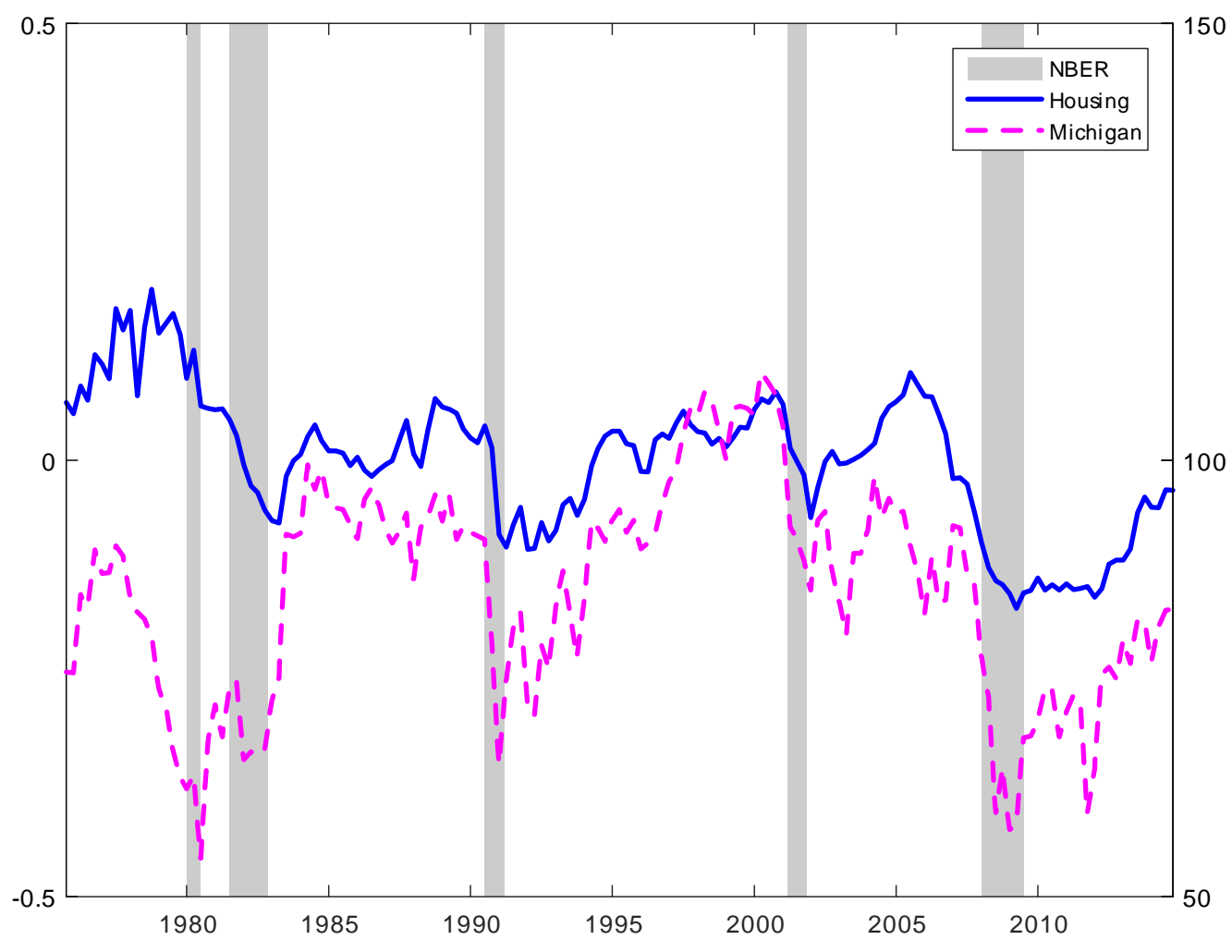

Figure 2. The housing sentiment index.

The figure plots the housing sentiment index joint with the Michigan sentiment index. The grey bars indicate NBER-dated recessions. 

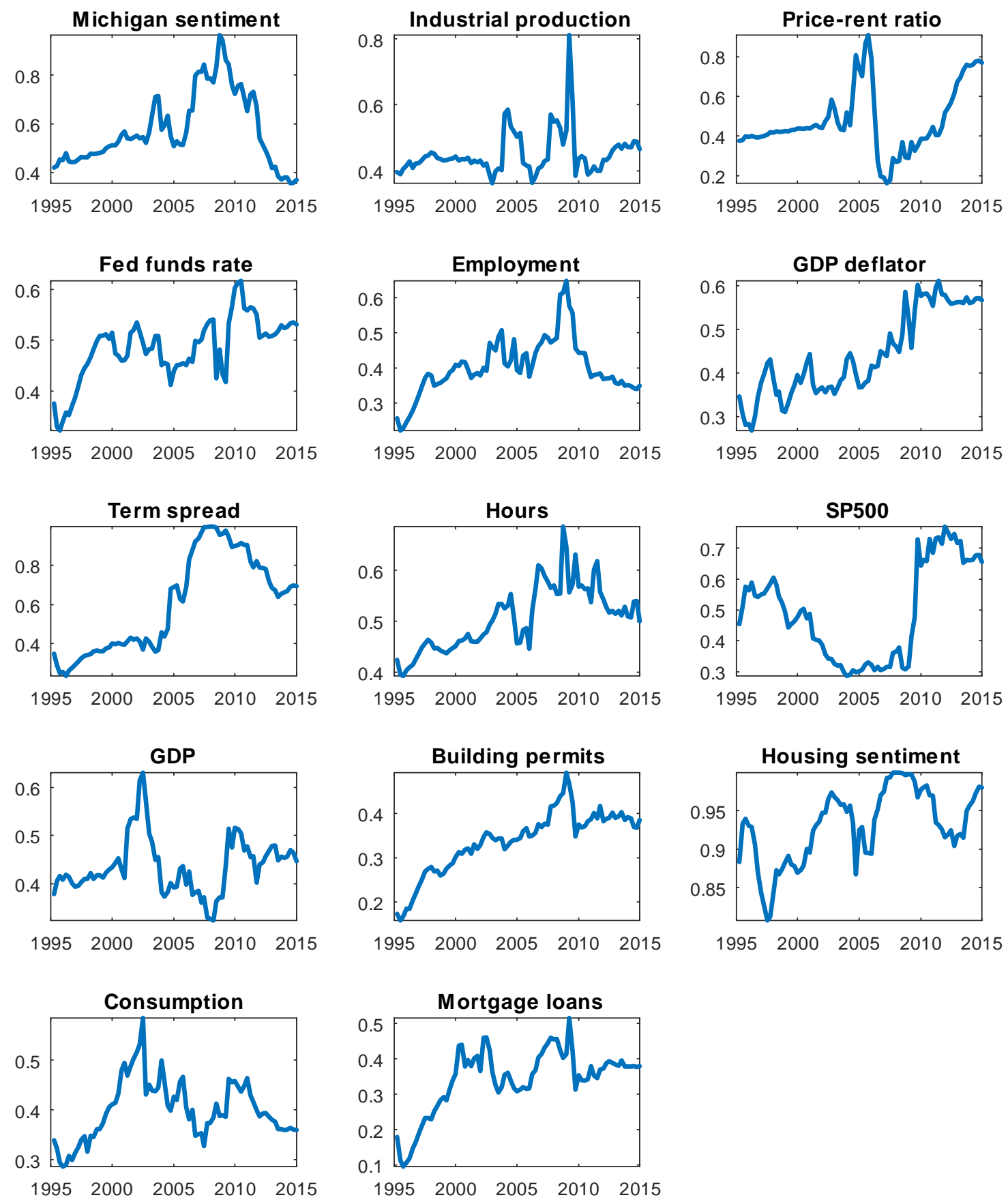

Figure 3. Posterior inclusion probabilities.

The figure plots posterior inclusion probabilities for each of the 14 predictive variables. 


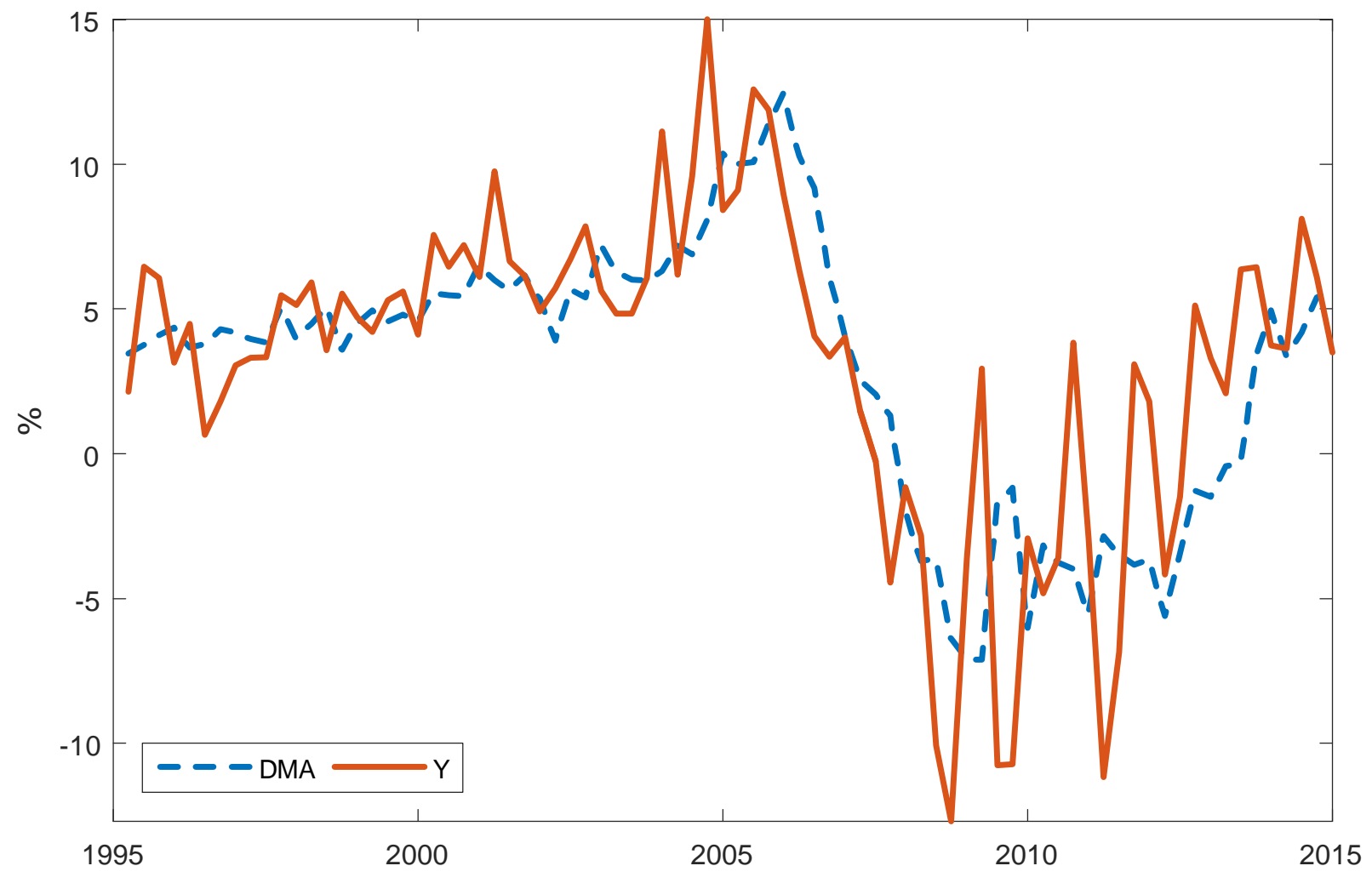

Figure 4. DMA forecasts.

The figure plots realized house price growth rates together with DMA forecasts (both are annualized). 

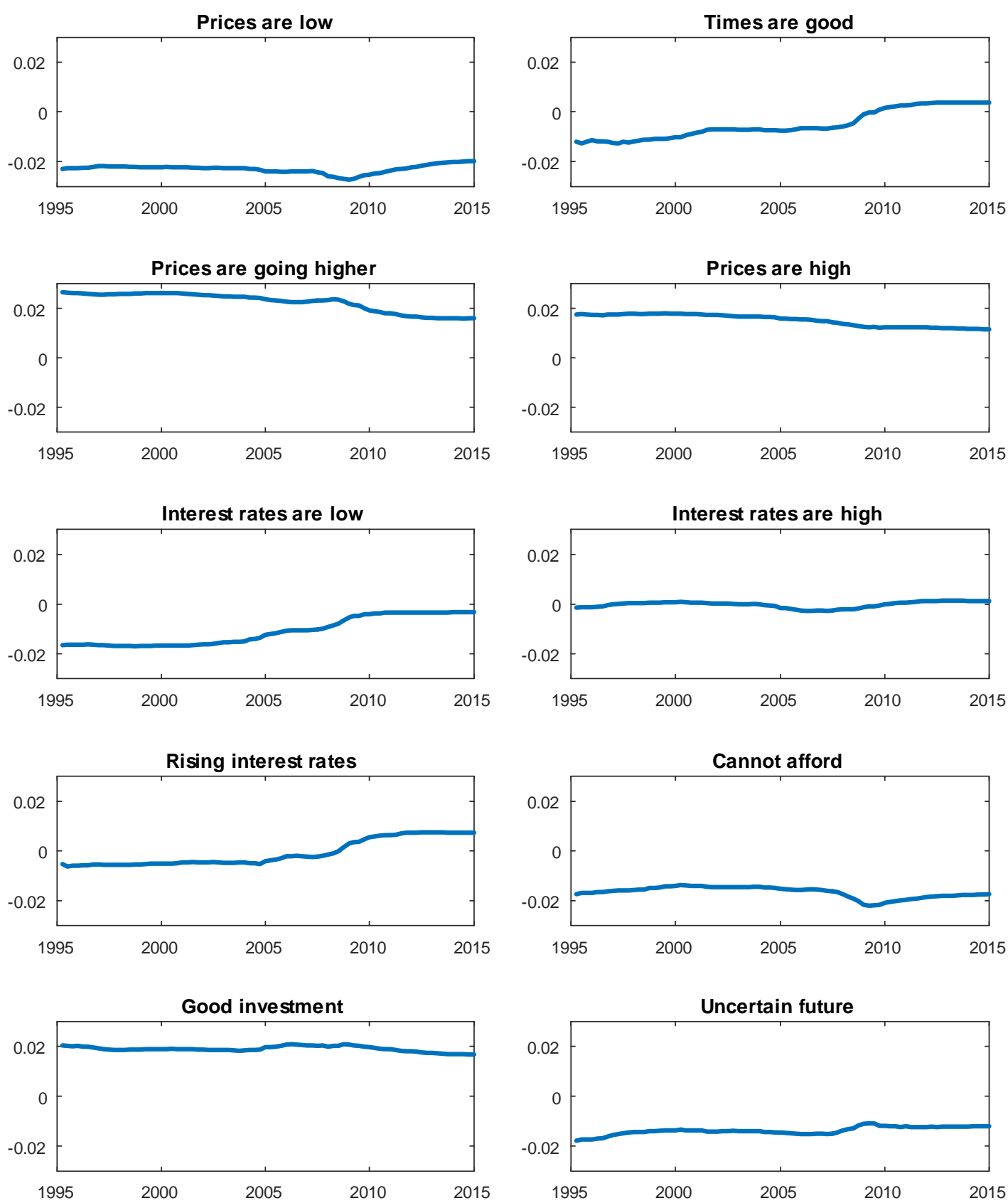

\section{Figure 5. Weights.}

The figure plots the PLS weights on the underlying components in the housing sentiment index. 

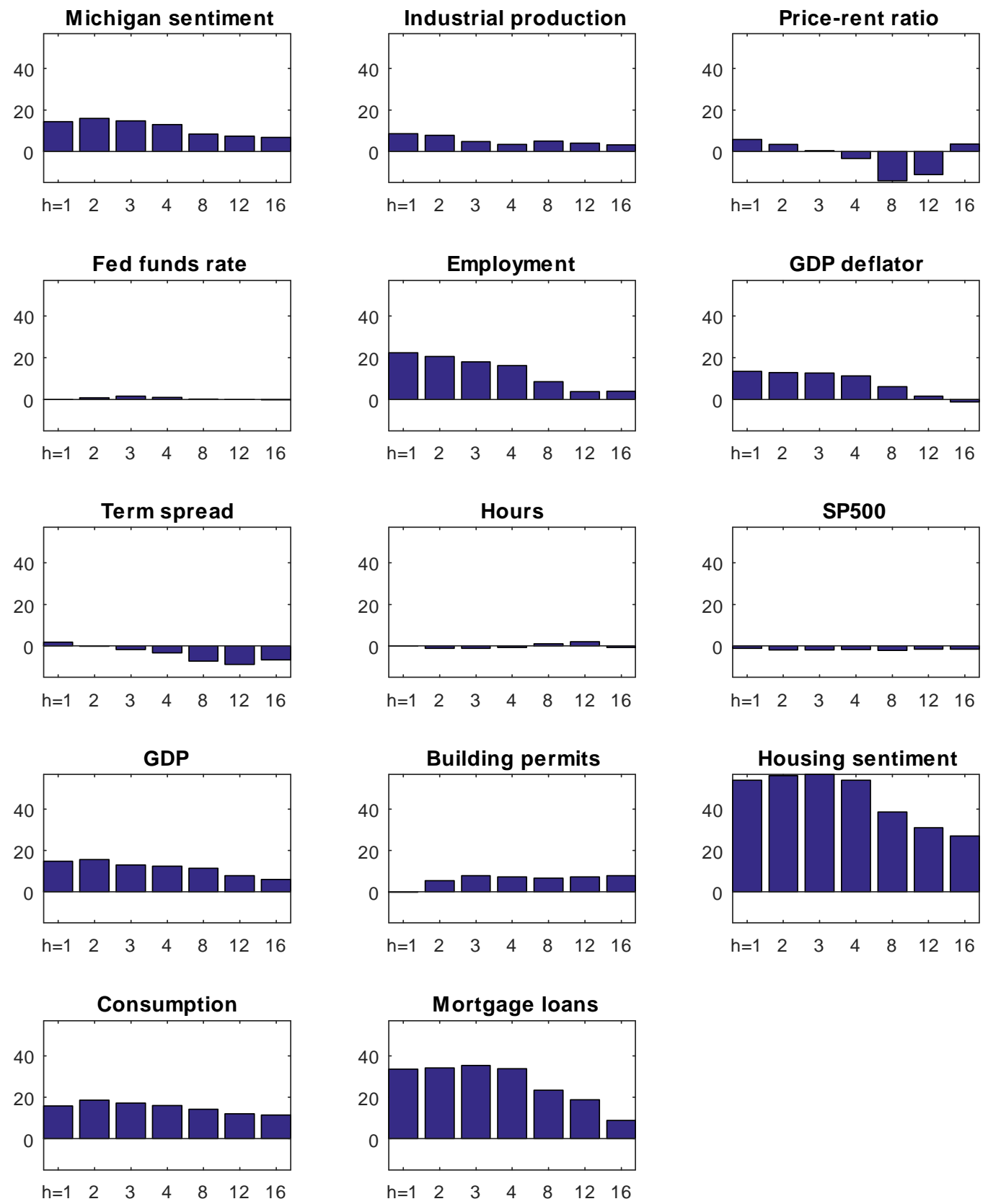

Figure 6. Predictive power at longer horizons.

The figure plots the $R_{O o S}^{2}$ for each of the individual predictor variables for forecast horizons of $h=1,2,3,4,8,12$, and 16 . 

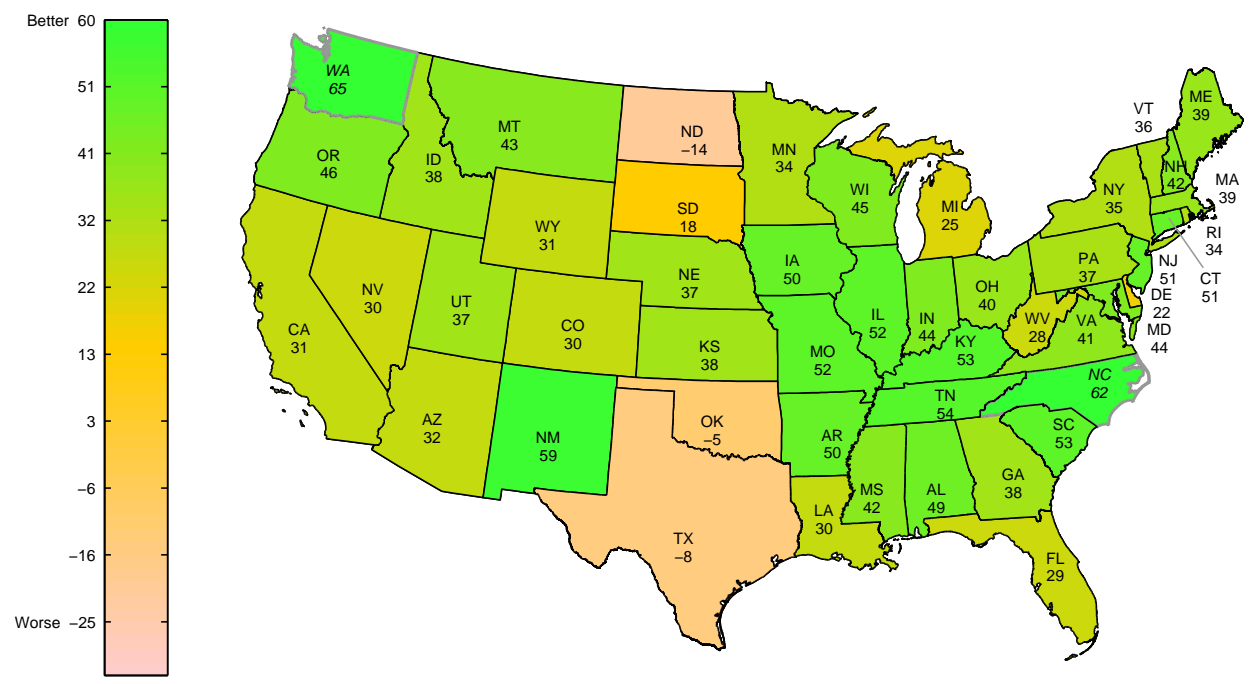

Figure 7. Out-of-sample $R^{2}\left(R_{O o S}^{2}\right)$.

The figure shows the Campbell and Thompson (2008) $R_{O o S}^{2}$ for the housing sentiment index versus the constant mean benchmark model across states. $R_{O o S}^{2} \leq 0$ corresponds to no predictability. 
Table 1. Summary statistics.

\begin{tabular}{lcrrrr}
\hline & & & & \\
Variable & Transformation & Mean & SD & AR1 & CORR \\
& & & & & \\
Housing sentiment & level & 0.00 & 0.08 & 0.95 & 1.00 \\
Michigan's sentiment index & level & 85.09 & 12.33 & 0.92 & 0.41 \\
Federal funds rate & $\Delta$ & -0.03 & 1.33 & -0.22 & 0.22 \\
Term spread & level & 1.31 & 1.68 & 0.75 & -0.43 \\
Real GDP & $\Delta \ln$ & 0.70 & 0.78 & 0.37 & 0.41 \\
Real consumption & $\Delta \ln$ & 0.75 & 0.62 & 0.34 & 0.36 \\
Industrial production & $\Delta \ln$ & 0.59 & 1.39 & 0.59 & 0.35 \\
Employment & $\Delta \ln$ & 0.38 & 0.53 & 0.81 & 0.59 \\
Average weekly hours in manufacturing & level & 40.77 & 0.68 & 0.93 & -0.10 \\
Building permits & $\Delta \ln$ & 0.25 & 10.44 & 0.11 & 0.04 \\
Mortgage loans outstanding & $\Delta \ln$ & 1.82 & 1.30 & 0.90 & 0.79 \\
Price-rent ratio & $\ln$ & 3.24 & 0.10 & 0.99 & -0.12 \\
GDP deflator & $\Delta \ln$ & 0.80 & 0.55 & 0.89 & 0.54 \\
S\&P500 stock price index & $\Delta \ln$ & 1.95 & 7.97 & 0.06 & 0.01 \\
& & & & & \\
\hline
\end{tabular}

The table shows summary statistics for the 14 predictive variables. For each variable, we report the mean, standard deviation (SD), first-order autocorrelation coefficient (AR1), and its correlation coefficient with housing sentiment (CORR). The table also shows how the variables have been transformed to ensure stationarity. The transformation codes are: "level" means no transformation; " $\Delta$ " means first-difference; and " $\Delta \ln "$ means log first-difference. All economic variables are obtained from St. Louis Fed's FRED database. The sample period is 1975:2-2014:4. 
Table 2. Results from in-sample tests.

\begin{tabular}{|c|c|c|c|c|c|c|c|c|}
\hline \multirow[b]{2}{*}{ Variable } & \multicolumn{3}{|c|}{ Panel A } & \multicolumn{5}{|c|}{ Panel B } \\
\hline & $\beta$ & $t_{N W}$ & $R^{2}$ & $\beta$ & $t_{N W}$ & $\phi$ & $t_{N W}$ & $R^{2}$ \\
\hline Housing sentiment & 10.98 & 8.52 & $47.7 \%$ & & & & & \\
\hline Michigan's sentiment index & 0.03 & 2.40 & $10.2 \%$ & 10.70 & 8.91 & 0.00 & 0.73 & $47.9 \%$ \\
\hline Federal funds rate & 0.03 & 0.39 & $0.1 \%$ & 11.42 & 8.79 & -0.12 & -2.76 & $49.2 \%$ \\
\hline Term spread & -0.11 & -1.33 & $2.2 \%$ & 12.31 & 8.81 & 0.15 & 2.98 & $50.7 \%$ \\
\hline Real GDP & 0.60 & 3.58 & $13.3 \%$ & 10.32 & 8.16 & 0.17 & 1.31 & $48.6 \%$ \\
\hline Real consumption & 0.71 & 3.14 & $12.2 \%$ & 10.32 & 8.83 & 0.24 & 2.42 & $48.9 \%$ \\
\hline Industrial production & 0.28 & 2.85 & $9.6 \%$ & 10.55 & 8.28 & 0.07 & 1.05 & $48.3 \%$ \\
\hline Employment & 1.11 & 4.20 & $21.7 \%$ & 10.14 & 6.81 & 0.21 & 0.91 & $48.3 \%$ \\
\hline Hours in manufacturing & -0.19 & -0.79 & $1.0 \%$ & 10.94 & 8.39 & -0.04 & -0.29 & $47.8 \%$ \\
\hline Building permits & 0.01 & 1.06 & $1.1 \%$ & 10.95 & 9.12 & 0.01 & 1.34 & $48.3 \%$ \\
\hline Mortgage loans outstanding & 0.56 & 5.74 & $32.8 \%$ & 10.11 & 4.65 & 0.07 & 0.53 & $47.9 \%$ \\
\hline Price-rent ratio & -3.11 & -1.51 & $6.1 \%$ & 10.65 & 9.61 & -2.07 & -1.95 & $50.4 \%$ \\
\hline GDP deflator & 0.89 & 2.91 & $14.8 \%$ & 10.84 & 7.69 & 0.04 & 0.22 & $47.8 \%$ \\
\hline S\&P500 stock price index & -0.00 & -0.02 & $0.0 \%$ & 10.98 & 8.46 & -0.12 & -0.11 & $47.7 \%$ \\
\hline
\end{tabular}

Panel A reports results from running forecasting regressions, $y_{t+1}=\alpha+\beta x_{t}+u_{t+1}$, where $y_{t+1}$ is the FHFA house price growth rate observed at time $t+1$ and $x_{t}$ is a predictive variable observed at time $t$. For each predictive variable, we report the slope estimate, the Newey-West $t$-statistic (three lags), and the $R^{2}$. Panel B contains the same results for the bivariate regression, $y_{t+1}=$ $\alpha+\beta S_{t}^{H}+\phi x_{t}+u_{t+1}$, where $S_{t}^{H}$ is the housing sentiment index and $x_{t}$ is another predictive variable. The sample period is 1975:2-2014:4. 
Table 3. Results from out-of-sample tests: OLS regressions.

\begin{tabular}{lrcc}
\hline Variable & $R_{\text {OoS }}^{2}$ & $\lambda_{S^{H}}$ & $\lambda_{j}$ \\
& & & \\
Housing sentiment & $54.2 \%(0.00)$ & & \\
Michigan's sentiment index & $14.3 \%(0.01)$ & $1.34(0.00)$ & $-0.34(0.10)$ \\
Federal funds rate & $0.0 \%(0.35)$ & $1.22(0.00)$ & $-0.22(0.13)$ \\
Term spread & $1.9 \%(0.14)$ & $1.27(0.00)$ & $-0.27(0.19)$ \\
Real GDP & $14.9 \%(0.07)$ & $1.18(0.00)$ & $-0.18(0.28)$ \\
Real consumption & $15.9 \%(0.03)$ & $1.26(0.00)$ & $-0.26(0.19)$ \\
Industrial production & $8.6 \%(0.17)$ & $1.15(0.00)$ & $-0.15(0.38)$ \\
Employment & $22.4 \%(0.06)$ & $1.08(0.00)$ & $-0.08(0.65)$ \\
Hours in manufacturing & $0.1 \%(0.39)$ & $1.24(0.00)$ & $-0.24(0.15)$ \\
Building permits & $-0.1 \%(0.44)$ & $1.20(0.00)$ & $-0.20(0.21)$ \\
Mortgage loans outstanding & $33.6 \%(0.01)$ & $1.68(0.00)$ & $-0.68(0.02)$ \\
Price-rent ratio & $5.8 \%(0.08)$ & $1.22(0.00)$ & $-0.22(0.21)$ \\
GDP deflator & $13.4 \%(0.01)$ & $1.24(0.00)$ & $-0.24(0.19)$ \\
S\&P500 stock price index & $-1.0 \%(0.76)$ & $1.24(0.00)$ & $-0.24(0.15)$ \\
& & & \\
\hline
\end{tabular}

We test the null hypothesis that the out-of-sample $R^{2}\left(R_{O o S}^{2}\right)$ is equal to zero or negative against the alternative that it is positive using the Clark-West (2007) test. $P$-values from the test are in parentheses. The table also reports results from Chong-Hendry (1986) forecasting encompassing regressions where we test the null hypotheses that the individual weights $\left(\lambda_{S^{H}}\right.$ and $\left.\lambda_{j}\right)$ are equal to zero and report $p$-values in parentheses. The out-of-sample window is from 1995:1 to 2014:4. 
Table 4. Results from out-of-sample tests: DMA.

\begin{tabular}{lccc}
\hline Model & $R_{\text {OoS }}^{2}$ & $\lambda_{D M A}$ & $\lambda_{j}$ \\
& & & \\
DMA & $60.7 \%(0.00)$ & & \\
DMA without housing sentiment & $48.9 \%(0.00)$ & $1.28(0.00)$ & $-0.28(0.12)$ \\
& & & \\
\hline
\end{tabular}

We test the null hypothesis that the out-of-sample $R^{2}\left(R_{O o S}^{2}\right)$ is equal to zero or negative against the alternative that it is positive using the Clark-West (2007) test. $P$-values from the test are in parentheses. The table also reports results from Chong-Hendry (1986) forecasting encompassing regressions where we test the null hypotheses that the individual weights $\left(\lambda_{D M A}\right.$ and $\left.\lambda_{j}\right)$ are equal to zero and report $p$-values in parentheses. The out-of-sample window is from 1995:1 to 2014:4. 
2016-15: $\quad$ Mikkel Bennedsen, Ulrich Hounyo, Asger Lunde and Mikko S. Pakkanen: The Local Fractional Bootstrap

2016-16: Martin M. Andreasen and Kasper Jørgensen: Explaining Asset Prices with Low Risk Aversion and Low Intertemporal Substitution

2016-17: Robinson Kruse, Christian Leschinski and Michael Will: Comparing Predictive Accuracy under Long Memory - With an Application to Volatility Forecasting

2016-18: $\quad$ Søren Johansen and Bent Nielsen: Tightness of M-estimators for multiple linear regression in time series

2016-19: Tim Bollerslev, Jia Li and Yuan Xue: Volume, Volatility and Public News Announcements

2016-20: $\quad$ Andrea Barletta, Paolo Santucci de Magistris and Francesco Violante: Retrieving Risk-Neutral Densities Embedded in VIX Options: a Non-Structural Approach

2016-21: Mikkel Bennedsen: Semiparametric inference on the fractal index of Gaussian and conditionally Gaussian time series data

2016-22: $\quad$ Søren Johansen and Morten Ørregaard Nielsen: The cointegrated vector autoregressive model with general deterministic terms

2016-23: $\quad$ Yunus Emre Ergemen and Carlos Vladimir Rodríguez-Caballero: A Dynamic Multi-Level Factor Model with Long-Range Dependence

2016-24: Shin Kanaya: Convergence rates of sums of a-mixing triangular arrays: with an application to non-parametric drift function

2016-25: Gustavo Fruet Dias, Marcelo Fernandes and Cristina M. Scherrer: Improving on daily measures of price discovery

2016-26: $\quad$ Martin M. Andreasen, Tom Engsted, Stig V. Møller and Magnus Sander: Bond Market Asymmetries across Recessions and Expansions: New Evidence on Risk Premia

2016-27: $\quad$ Kim Christensen, Ulrich Hounyo and Mark Podolskij: Testing for heteroscedasticity in jumpy and noisy high-frequency data: A resampling approach

2016-28: Kim Christensen, Roel Oomen and Roberto Renò: The Drift Burst Hypothesis

2016-29: Hossein Asgharian, Charlotte Christiansen, Rangan Gupta and Ai Jun Hou: Effects of Economic Policy Uncertainty Shocks on the Long-Run US-UK Stock Market Correlation

2016-30: $\quad$ Morten Ørregaard Nielsen and Sergei S. Shibaev: Forecasting daily political opinion polls using the fractionally cointegrated VAR model

2016-31: $\quad$ Carlos Vladimir Rodríguez-Caballero: Panel Data with Cross-Sectional Dependence Characterized by a Multi-Level Factor Structure

2016-31: $\quad$ Lasse Bork, Stig V. Møller and Thomas Q. Pedersen: A New Index of Housing Sentiment 